\title{
Short Term Climate Trend and Variability around Woliso, Oromia Region, Central Ethiopia
}

\author{
Solomon Tekalign*
}

School of Geography and Environmental Studies, Haramaya University, P.O. Box: 33, Dire Dawa, Ethiopia

\begin{tabular}{|c|c|}
\hline Abstract & ntol \\
\hline \multirow{11}{*}{$\begin{array}{l}\text { Based on the meteorological data of Woliso for the last decade }(2004-2013) \text {, short-term } \\
\text { climate variability was assessed. Computation were made to identify mean monthly, seasonal } \\
\text { and annual temperature patterns and deviations, linear trends and } \mathrm{R}^{2} \text { values, rainfall } \\
\text { coefficient, rainfall intensity, water surplus and deficit, and moisture region of Woliso area. The } \\
\text { findings showed the presence of almost uniform pattern of both temperature and rainfall. The } \\
\text { temperatures showed significant decrement in its minimum and increment in its maximum, and } \\
\text { mean annual temperature by about }-0.3,+1.28 \text {, and }+0.49{ }^{0} \mathrm{C} \text {, respectively over the last } \\
\text { decade. Similarly, seasonal variability were identified with increment in the winter, summer and } \\
\text { autumn by } 1.13,2.78 \text { and } 0.9^{\circ} \mathrm{C} \text {, respectively while it showed decrement in the spring by }-0.5 \\
{ }^{0} \mathrm{C} \text {. About } 60 \% \text { of the years }(2004,2005,2008,2009 \text { and } 2011) \text { experienced low rainfall } \\
\text { intensity while } 40 \% \text { of them }(2006,2007,2010 \text { and } 2013) \text { had medium rainfall intensity. The } \\
\text { only year which experienced extreme rainfall intensity was in } 2012 \text {. Six months (ONDJFM) } \\
\text { were dry (low RC < }<0.6) \text {, whereas May and September received big rains with moderate } \\
\text { concentration (rainfall coefficient }=1.0-1.9) \text { and the summer (JJA) received big rainfall with high } \\
\text { concentration (rainfall coefficient=2.0-2.9). The climate type of Woliso was under Dry sub- } \\
\text { humid }\left(\mathrm{C}_{1}\right) \text { that also requires further water development schemes to supplement the life and } \\
\text { livelihood especially during the dry months. However, such findings should be scrutinized as } \\
\text { the current report used only a decade's data }\end{array}$} & \\
\hline & Received : 20-07-2015 \\
\hline & vised \\
\hline & \\
\hline & attern \\
\hline & \\
\hline & all \\
\hline & \\
\hline & nd \\
\hline & \\
\hline & \\
\hline
\end{tabular}

\section{INTRODUCTION}

There is a worldwide consensus that global warming is a real, rapidly advancing and widespread threat facing humanity in this century more than ever. Scientists have presented evidence and tested models to substantiate this truly alarming fact (Chaudhary and Aryal, 2009). Climate change and variability (CVV) certainly has an effect on the future sustainable development of much of our resources and various sectorial activities of the globe (WMO, 1992). It is one of the most challenging environmental stresses that affect sets of activities (Valdivia and Quiroz, 2003). There are uneven occurrences of changes in temperature and precipitation and hence its impacts will also be unevenly distributed around the globe. It is also recognized that even within regions impacts, adaptive capacity and vulnerability will vary (IPCC, 2001). Africa has contributed the least to the amount of global emission of greenhouse gases, and has the least capacity to adapt and thus the most vulnerable to the adverse effects of $\mathrm{CCV}$. It lacks the necessary institutional, economic and financial capacity to cope with CVV impacts and to rebuild the infrastructure damaged by natural disasters (Huq, 2003). At inter- and intra national as well as at various sectoral levels, different groups of population have been identified as being more or less at-risk due to changing climate depending on length of coastline, level of emergency preparedness and economic and livelihood sensitivity as well as exposure and resilience status to climate variability and change (IPCC, 2007).
Since rainfed agriculture employs about $80 \%$ of the population and forms the basis of the economy of Ethiopia (EEA, 2014), any variability and changes in climate are directly reflected on the overall biophysical and human phenomena of the nation. Ethiopia demonstrates diverse geo-physical and climatic conditions within relatively small areas. Thus, it is the imperative to assess the major features of short term trends and variability in climate of the study area in the last one decade so as to identify peculiarities of any variation in the micro climate and thereby forward possible recommendations.

\section{MATERIALS AND METHODS}

Descriptive research approach was designed to conduct this study. Temperature and rainfall data of Woliso station for the last decade (2004-2013) were collected from the National Meteorological Service Agency (NMSA). Simple bookkeeping quantitative and descriptive statistics were used to compute monthly, seasonal, annual, five-year cycles and decadal temperature and rainfall distributions, trends and variability at Woliso. These include rainfall intensity, moving/running/overlapping means, normal means, average deviation, standard deviation, relative variability, linear trend analysis and regressions, and coefficient of variation $(\mathrm{CV})$. Proper secondary data were retrieved to substantiate information obtained from the primary sources and their respective analysis. Statistical figures, 
Solomon Tekalign

graphs and tables were used to interpret and further explain the facts on climate trends and variability.

\section{Profile of the Study Area}

Woliso (which was also used to be known as Ghion, after being given by Emperor Haile Selassie I) is a town, and administrative center of Woliso woreda, in the Debub Mirab Shewa Zone of Oromia Region, central Ethiopia. The astronomical location of Woliso is $08^{0} 46^{\prime} \mathrm{N}$ Latitude and $37^{\circ} 58 \mathrm{E}$ Longitude being situated at 2,063masl and $114 \mathrm{~km}$ southwest of Addis Ababa.

\section{Demographics}

According to the CSA (2007), Woliso had a total population of 37,878 , of which, $18,800(49.84 \%)$ were male while the other $18,998(50.16 \%)$ were female in sex. The majority (about $63.29 \%$ ) of the population practiced
Sci. Technol. Arts Res. J., July-Sep 2015, 4(3): 129-138

Ethiopian Orthodox Christianity while $19.06 \%$ and $16.36 \%$ of them were Protestants and Muslims, respectively.

\section{RESULTS AND DISCUSSION}

\section{Climate Feature}

The wettest month was July that received about $312 \mathrm{~mm}$ in the last decade (2004-13). The months from October till April received low amount of rainfall (Fig.1). Based on the average temperature of the warmest and the coldest months, the altitude and the Potential Evaporation (PE) value used by Daniel (1977 employing emperical formulae of Thornthwait 1948, Thornthwaite and Mather 1957 and Meigs 1953), Woliso has largely subtropical (traditional identified as woina dega) agroecological zone. The mean potential evapotranspiration (PET) in the last one decade ranges from $59.56 \mathrm{~mm}$ (July) to $68.42 \mathrm{~mm}$ (February) in the study area while its annual average was about $761 \mathrm{~mm}$.

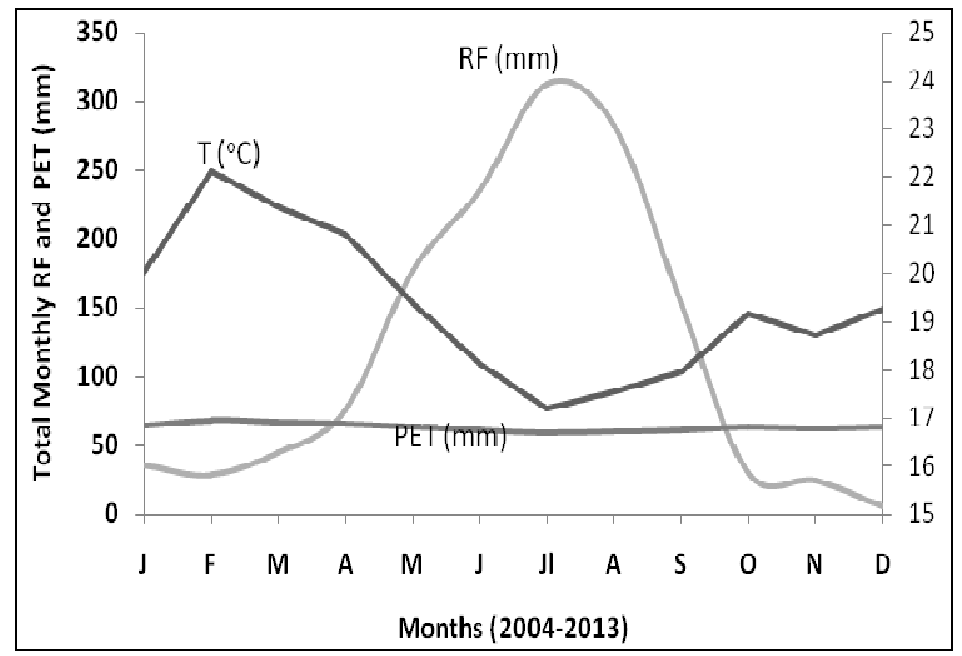

Figure 1: Monthly temperature, rainfall and potential evapotranspiration at Woliso

\section{Temperature Patterns and Variability}

Air temperature is one of the most predominant and very vital elements of climate for it is very observable and has invaluable effect on life and livelihood of human beings. Analyses of the annual, seasonal and monthly temperature of the study area over the last decade (200413) are discussed as under.

\section{Annual Temperature}

The average minimum, maximum and mean annual temperatures of Woliso were about $13.6,25$ and $19.3^{\circ} \mathrm{C}$, respectively (Table 1 ). Of these, there was similarity in the minimum annual temperature except in the case of 2006 and 2009 where there was relatively higher record of minimum annual temperature compared to the aggregate mean in the last decade (Figure 2). Instead of using the mean and standard deviation that tend to change, the relative variability in the annual temperature was examined by using CV for it is relatively stable, constant and easy to remember (Snedecor and Cochran 1989). Thus, based on the mean $\left(19.3^{\circ} \mathrm{C}\right)$ and standard deviation $\left(0.41{ }^{\circ} \mathrm{C}\right)$, the $\mathrm{CV}$ was found nearly $2 \%$ for that implies very insignificant relative variability in annual temperature of Woliso during the study period. This can also be seen from the linear trend equation and the $R^{2}$ values whereby the $R$ values for all the cases were below 0.5 (Figure 2) that implies little/no relative variability.
Simple algebraic mathematics to identify running/ moving means (as employed by Awol 2010) was used to identify departures in the average minimum, maximum and minimum annual temperature from 2004 through 2013. It was identifeid that the annual minimum, maximum and mean temperature showed variation by about -0.3 , 1.23 and $0.49{ }^{\circ} \mathrm{C}$, respectivley around Woliso (Table 1). Likewise, according to the linear trend equation chart, there was negative trend in the minimum annual temperature while positive in the case of maximum and mean annual temperature of the study area. However, the $R$ values of the minimum, mean and maximum annual temperature were $0.05,0.1$ and 0.24 , respectively that were below 0.5 implying insignificant change in the annual temperature records in the last decade (Figure 2). This seems to vary from the $\left(0.3{ }^{0} \mathrm{C}\right)$ increase reported by Muna (2006) for the annual mean for the Ethiopian highlands and the average annual minimum and maximum temperature increased over the country by about $0.37{ }^{\circ} \mathrm{C}$ and $0.1{ }^{0} \mathrm{C}$ every decade, respectively reported in NMSA (2007). But this needs to be scrutinized by further investigation since the longer the period of averaging the closer the average will come to the true long-term averaging and vice versa (Strahler and Strahler 1997). 
Table 1: Normal, moving average and variations in the maximum, minimum and mean temperature of Woliso

\begin{tabular}{ccccccc}
\hline Year & Min & Variations & Max & Variations & Mean & Variations \\
\hline 2004 & 13.38182 & 0 & 24.0167 & 0 & 18.6992 & 0 \\
2005 & 13.52727 & 0.14545 & 25.425 & 1.4083 & 19.4761 & 0.7769 \\
2006 & 14.67273 & 1.14546 & 25.0333 & -0.3917 & 19.853 & 0.3769 \\
2007 & 13.49091 & -1.1818 & 25.2917 & 0.2584 & 19.3913 & -0.4617 \\
2008 & 13.18182 & -0.3091 & 25.2 & -0.0917 & 19.1909 & -0.2004 \\
2009 & 14.30909 & 1.12727 & 25.9 & 0.7 & 20.1045 & 0.9136 \\
2010 & 13.82727 & -0.4818 & 25.25 & -0.65 & 19.5386 & -0.5659 \\
2011 & 13.29091 & -0.5364 & 25.1583 & -0.0917 & 19.2246 & -0.314 \\
2012 & 13.65455 & 0.36364 & 23.8583 & -1.3 & 18.7564 & -0.4682 \\
2013 & 13.08182 & -0.5727 & 25.2917 & 1.4334 & 19.1867 & 0.4303 \\
\hline Variations & \multicolumn{7}{c}{$\mathbf{1 . 2 7 5}$} \\
\hline Normal Mean & $\mathbf{1 3 . 6 4}$ & $\mathbf{- 0 . 3}$ & $\mathbf{2 5 . 0 4}$ \\
\hline \multicolumn{7}{c}{ Source: Computed from data NMSA and adopted from Awol (2010); NB: Annual } \\
Variations= Summation of annual moving/running averages occurred per year
\end{tabular}

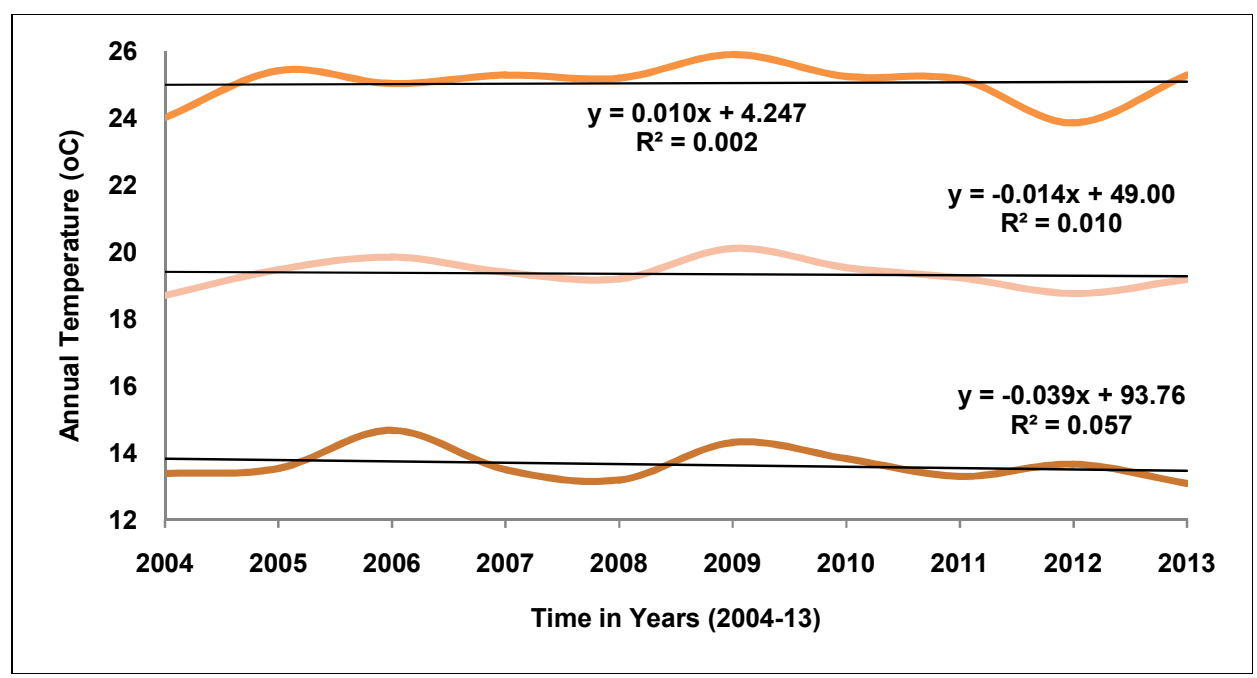

Figure 2: Annual average minimum, maximum and mean temperature

Seasonal Temperature Pattern and Variability

As disclosed in Table 2, the mean seasonal temperature ranges from $17.62^{\circ} \mathrm{C}$ in summer (cold, JJIA) to $20.5^{\circ} \mathrm{C}$ (in winter, DJF and autumn, SON). Based on the moving/overlapping mean, there was increase in the temperature of three seasons (namely summer, winter and autumn by about $2.78,1.13$ and $0.9{ }^{\circ} \mathrm{C}$, respectively, while it decreased by $-0.47{ }^{\circ} \mathrm{C}$ in spring (MAM) from 20042013. There was also high variability in seasonal temperatures, highest being in winter season of 2006 and 2009 while it was lowest in 2004. The lowest mean seasonal record was identified in summer of 2012 (Table 2 and Figure 3).

Table 2: Normal mean, moving average and seasonal temperature variations at Woliso

\begin{tabular}{|c|c|c|c|c|c|c|c|c|}
\hline Year & Winter & Variations & Spring & Variations & Summer & Variations & Autumn & Variations \\
\hline 2004 & 18.88 & 0 & 20.43 & 0 & 17.57 & 0 & 18.05 & 0 \\
\hline 2005 & 20.02 & 1.13 & 21.28 & 0.85 & 18.23 & 0.67 & 18.63 & 0.58 \\
\hline 2006 & 22.73 & 2.72 & 20.05 & -1.23 & 17.42 & -0.82 & 19 & 0.37 \\
\hline 2007 & 20.23 & -2.5 & 21.18 & 1.13 & 17.6 & 0.18 & 18.57 & -0.43 \\
\hline 2008 & 20.32 & 0.08 & 21 & -0.18 & 17.22 & -0.38 & 18.42 & -0.15 \\
\hline 2009 & 21.77 & 1.45 & 21.32 & 0.32 & 18.17 & 0.95 & 18.98 & 0.57 \\
\hline 2010 & 20.22 & -1.55 & 20.72 & -0.6 & 17.85 & -0.32 & 19.35 & 0.37 \\
\hline 2011 & 20.05 & -0.17 & 20.35 & -0.37 & 17.78 & -0.07 & 18.85 & -0.5 \\
\hline 2012 & 20.02 & -0.03 & 18.97 & -1.38 & 16.65 & -1.13 & 17.4 & -1.45 \\
\hline 2013 & 20.02 & 0 & 19.97 & 1 & 17.7 & 1.05 & 18.95 & 1.55 \\
\hline Variations & & 1.13 & & -0.47 & & 2.78 & & 0.9 \\
\hline Normal Mean & 20.46 & & 20.53 & & 17.62 & & 18.62 & \\
\hline
\end{tabular}

Source: Computed Based on Data from NMSA; Annual Variations= Summation of annual moving/running averages occurred per year. 


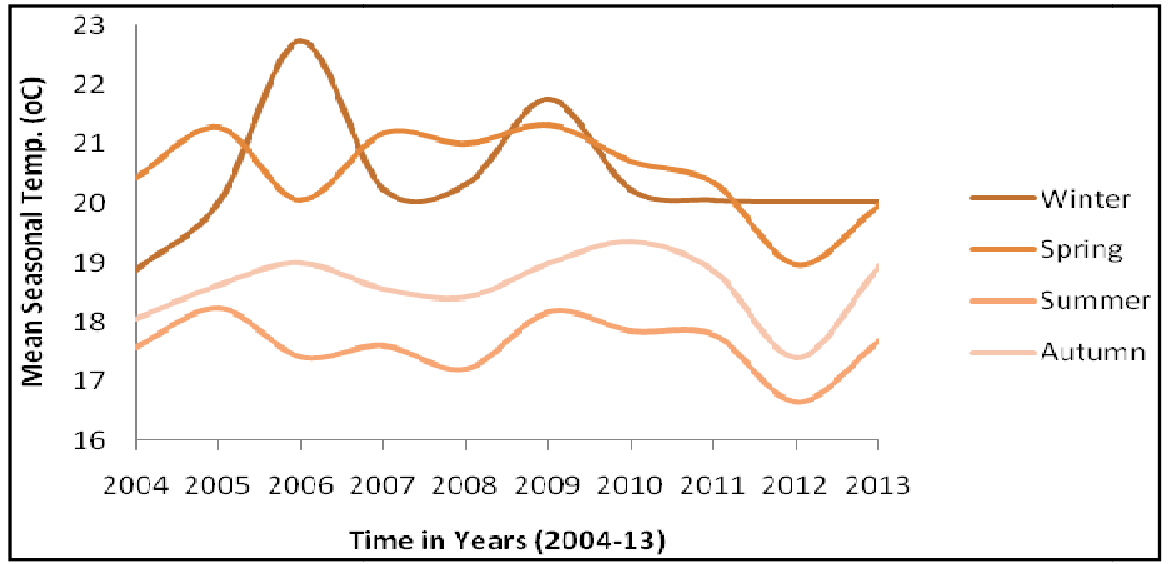

Figure 3: Seasonal pattern of temperature (2004-2013)

\section{Monthly Temperature Pattern and Variability}

There were exceptional variations in mean monthly temperatures at Woliso, which was found below aggregate mean in most months of 2004 and few months (MJJIN) of 2012. While that of February was found above the monthly mean in both 2006 and 2009 (Figure 4). The linear trend equation and the $R$ value of the chart of average monthly minimum, maximum and mean temperature of Woliso depicted in Figure 4. There were negative values that imply decrement in the average monthly minimum, mean and maximum temperature. Their $R$ values were $<0.5$ justifying insignificance in the decrement of monthly temperature (Figure 4). The deviation of monthly temperature was above the decadal mean from January to March while it was below the decadal mean from June through December (Figure 5).

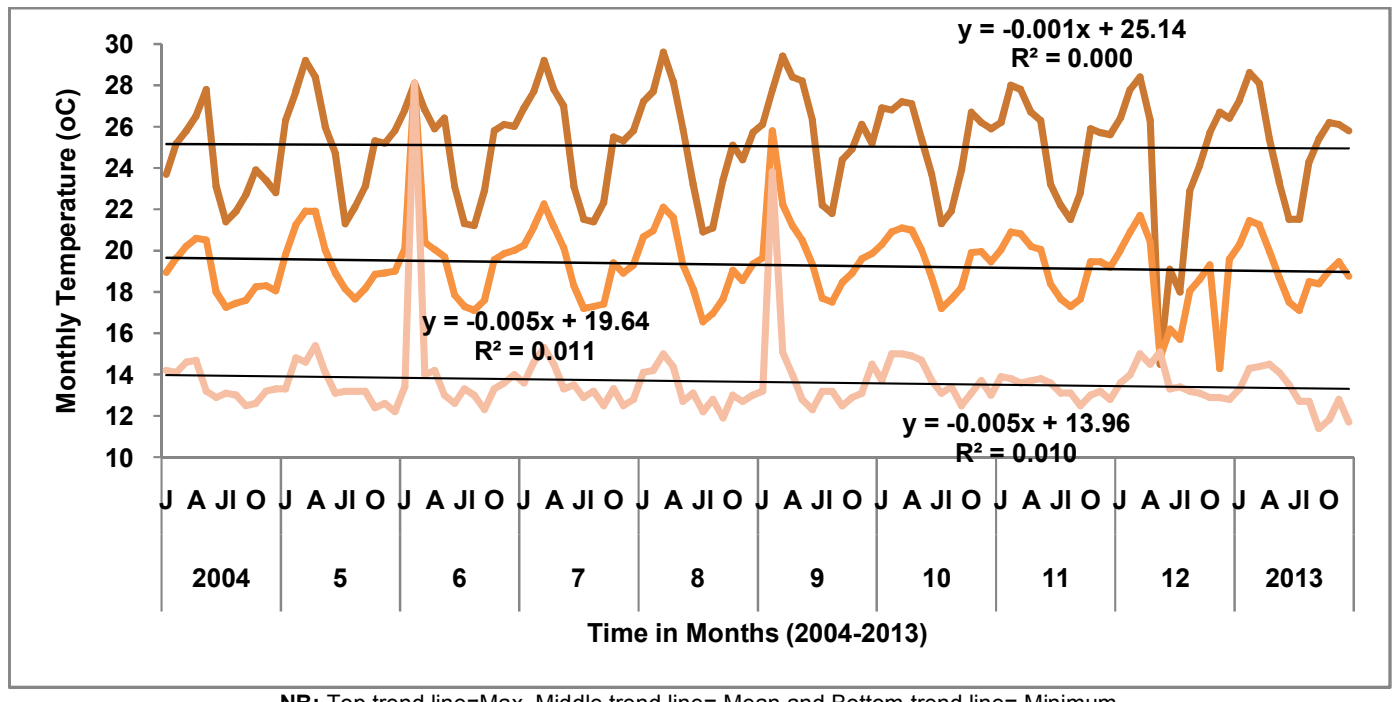

NB: Top trend line=Max, Middle trend line= Mean and Bottom trend line= Minimum

Figure 4: Trend of Minimum, Mean and Maximum Monthly Temperature of Woliso

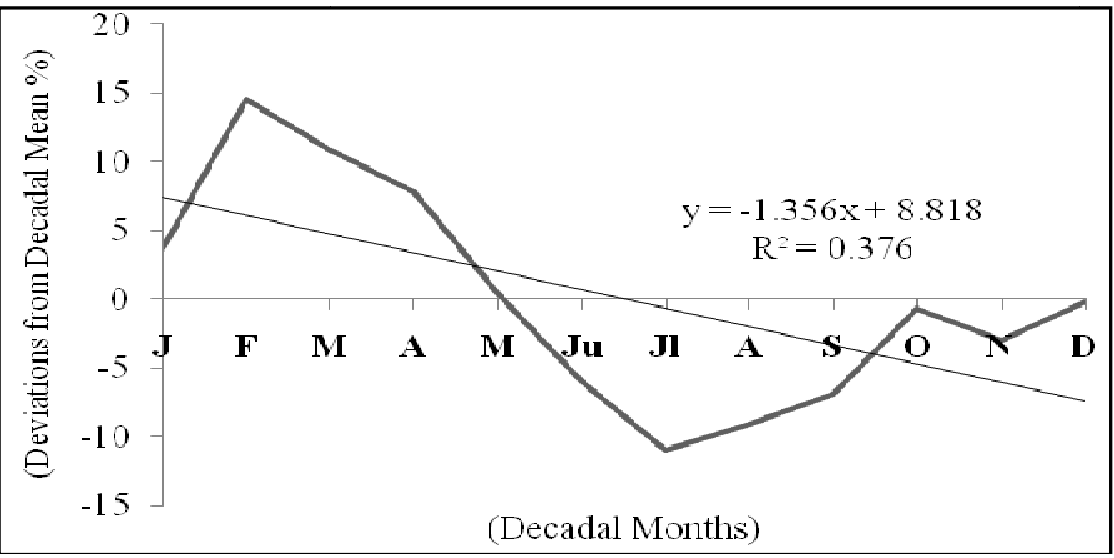

Figure 5: Deviations from decadal mean temperature (2004-2013) 


\section{Solomon Tekalign}

\section{Five Years' Cycles Temperature}

Often five years cycle also used to examine the effect of solar inclination on the mean monthly temperature of a station (Starhler and Strahler, 1997). As Figure 6 indicates, the general trend of mean monthly temperature of the five year cycles were evidient with slight variation during the first 5 years cycle (2004-2008), especially

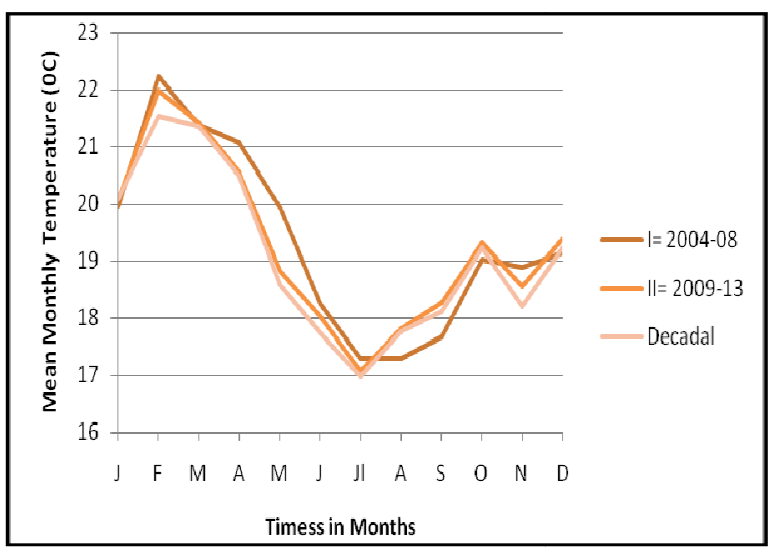

Sci. Technol. Arts Res. J., July-Sep 2015, 4(3): 129-138

positive deviation from decadal mean during 6/12 months (FAMJJIN) and with negative deviation in $5 / 12$ months (JASOD). In the second five year cycle (2009-13), there is overall positive deviation from the decadal mean with slight congruence and major difference in the overall trend of the deviation (Figure 6).

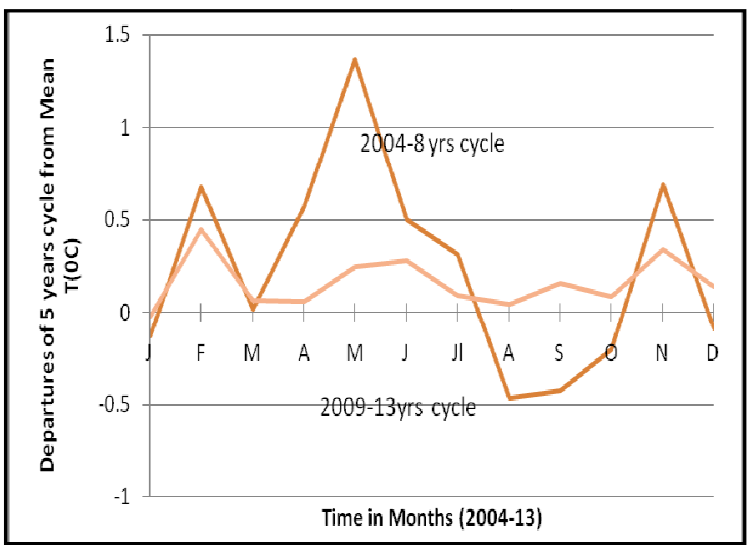

Figure 6: Patterns of 5 years cycles of mean monthly temperature (Left) and departure of five years' monthly temperature from the Mean (Right)

\section{Rainfall Distribution, Intensity and Variability}

The distribution in the average annual rainfall of Woliso over the last one decade (2004-2013) was almost uniform. The amount of annual average rainfall was about $1404.76 \mathrm{~mm}$, ranging from $950 \mathrm{~mm}$ in 2009 to $2,718.3 \mathrm{~mm}$ in 2012 (Figure 7a).

With regards to the trend of distribution over the last decade, the linear equation of the chart of the decadal

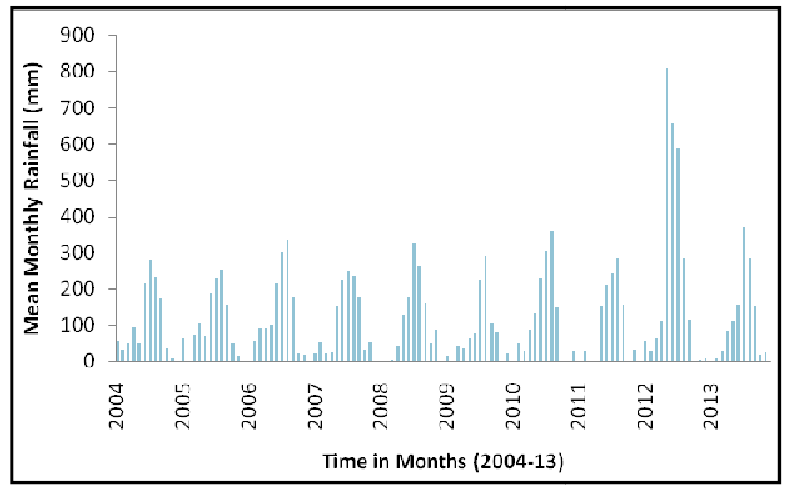

variation shows positive trends while its $R^{2}$ value was 0.122 (i.e. $R=0.4$ ), which implies insignificant increase in the rainfall distribution (Figure $7 \mathrm{~b}$ ). In the case of pattern of mean monthly rainfall distribution, 5/12 months (MJJIAS) received relatively higher amount of mean monthly rainfall whereas the other $7 / 12(58 \%)$ of the months received relatively low amount of mean monthly rainfall in the last one decade (Figure $7 b$ ).

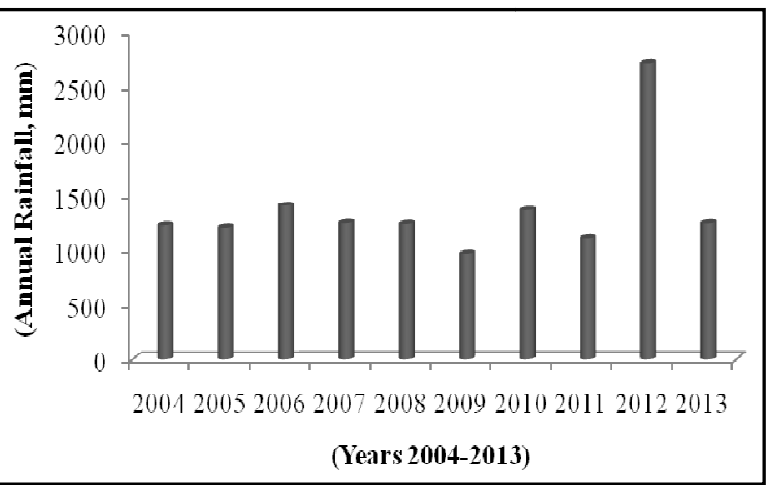

Figure 7a: Patterns of mean annual rainfall distribution (2004-13)
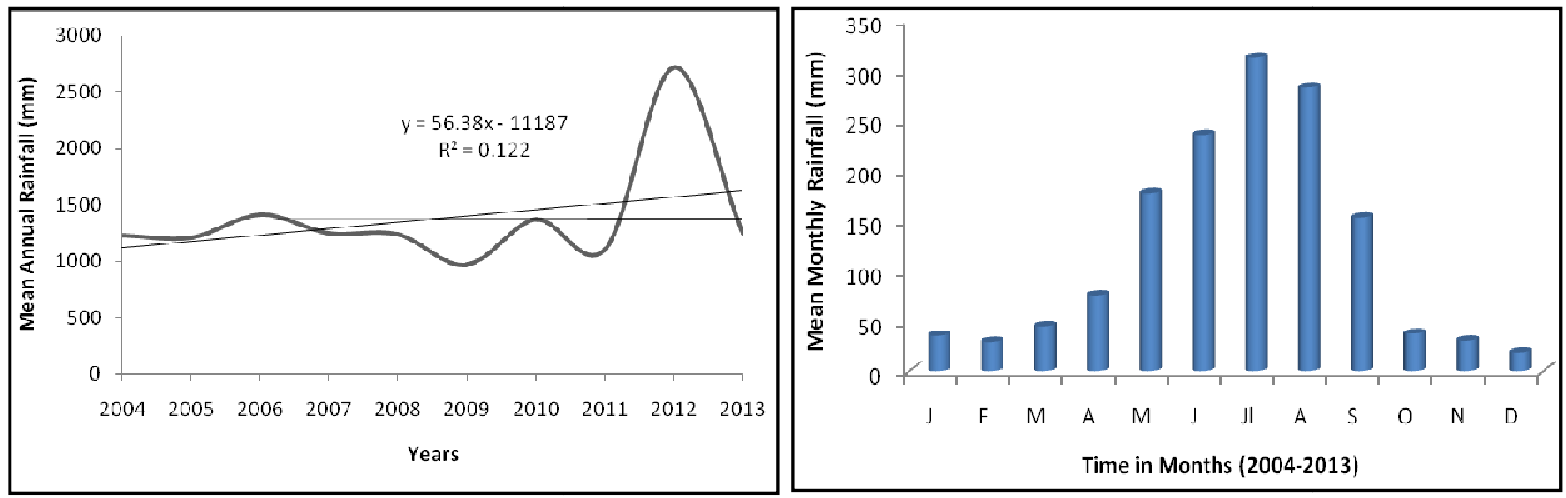

Figure 7b: Patterns of trend line of mean annual (Left) and monthly rainfall (Right) 


\section{Solomon Tekalign}

\section{Rainfall Seasonality}

The pattern of seasonality was determined by computing the value of rainfall concentration (RC) for each month based on the method employed by the UNFAO (1965 adopted by Daniel, 1977). According to Table 3, Woliso received small rains in 6/12 months (ONDJFM) as the RC is $<0.6(60 \%)$. They were dry and water deficit months, which require additional water supply to supplement life and livelihood activities of the community. In general, half of the years (AMJJAS) are rainy periods for their $\mathrm{RC}>0.6$. Five of them (MJJAS) were with big rainy months as their $\mathrm{RC}=\geq 1.0$. Woliso area received big rains with moderate concentration during May and September as their RC>2.0 while summer (JJA) season experienced highest concentration of big rains. When the seasonal distribution of rainfall of Woliso was concerned, the summer season recieved about 59\% followed by spring received nearly $1 / 5^{\text {th }}$ of the total rainfall (Figure 8).
Sci. Technol. Arts Res. J., July-Sep 2015, 4(3): 129-138

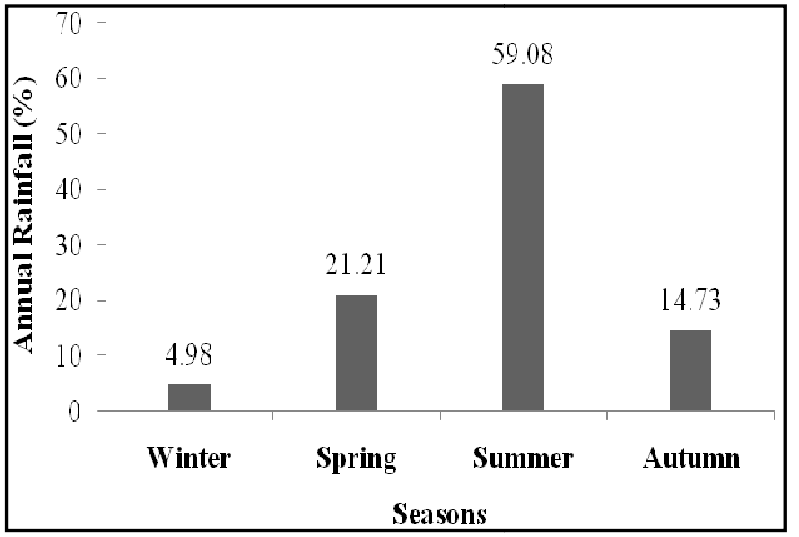

Figure 8: Percentage distribution of seasonal rainfall of woliso

Table 3: Mean Monthly Rainfall and Rainfall Concentration ( $P$ and $R C$ are in $\mathrm{mm}$ )

\begin{tabular}{ccccccccccccc}
\hline & Jan & Feb & Mar & Apr & May & June & July & Aug & Sep & Oct & Nov & Dec \\
\hline $\mathbf{P}$ & 35.45 & 28.9 & 44.97 & 75.83 & 177.19 & 235.31 & 312.09 & 282.48 & 152.7 & 29.91 & 24.33 & 5.6 \\
RC $^{1}$ & 0.3 & 0.25 & 0.38 & 0.64 & 1.51 & 2.01 & 2.67 & 2.41 & 1.3 & 0.26 & 0.21 & 0.05 \\
Desg. $^{2}$ & Dry $^{3}$ & Dry $^{3}$ & Dry $^{3}$ & Rainy $^{4}$ & BRM $^{5}$ & BRH $^{6}$ & BRH $^{6}$ & BRH $^{6}$ & BRM $^{5}$ & Dry $^{3}$ & Dry $^{3}$ & Dry $^{3}$ \\
\hline \multicolumn{8}{c}{ Source: Getachew et al. (2014). }
\end{tabular}

\section{Rainfall Intensity}

Rainfall intensity $(\mathrm{RI})$ is usually computed by taking the deviation of the annual rainfall from the median (Awol 2010). The deviation was identified using the standard deviation, which is the most powerful measure of assessment and most suitable for algebraic calculation that is always definite and used for higher statistical operations where great precision is required (Alvi, 1995; Koul, 1994). In this case, the median of the annual rainfall of the last decade was $1244.7 \mathrm{~mm}$ and its standard deviation was 392.73. Based on the RI index, half of the years (namely 2004, 2005, 2008, 2009 and 2011) experienced low intensity as their deviation was below 0 (Table 4). The moderate rainfall intensity occurred in $4 / 10$ years including 2006, 2007, 2010 and 2013. Yet, 2012 was the only year which experienced extreme rainfall intensity (Table 4 and Figure 9).

Table 4 Rainfall intensity (RI) categorization for Woliso during 2004-2013

\begin{tabular}{ccccc}
\hline Index & Deviations & RI & Years & No of Years \\
\hline$<0$ & $<0$ & Low & $2004,2005,2008,2009,2011$ & 5 \\
$0-1 / 2 \sigma$ & $0-196.37$ & Moderate & $2006,2007,2010,2013$ & 4 \\
$1 / 2 \sigma-\sigma$ & $196.37-392.73$ & High & NA & NA \\
$\sigma-2 \sigma$ & $392.73-785.46$ & Very High & NA & NA \\
$>2 \sigma$ & $>785.46$ & Extreme & 2012 & 1 \\
\hline & & & Total & $\mathbf{1 0}$
\end{tabular}

NB: $\mathrm{RI}=$ based on the deviations of the annual rainfall amounts from the median.

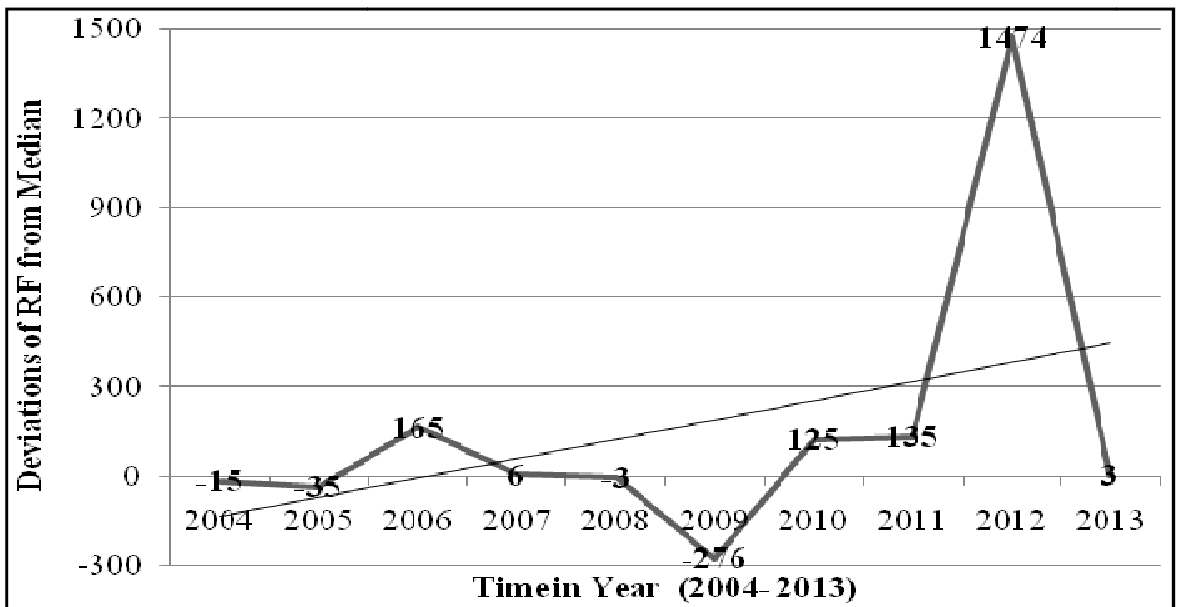

Figure 9: Deviations of annual mean rainfall from the median (2004-2013) 


\section{Solomon Tekalign}

\section{Rainfall Variability}

In countries like Ethiopia where the economy is predominated by rainfed agriculture system, assessment of rainfall variability (RV) is very influential to demarcate rainfall distribution over a given period of time. Moreover, it can also be used as indicative for proper interventions in agriculture, water harvesting, land management, etc (Solomon, 2013). Rainfall over a sequence of years is affected among others by the sun's declination cycle that can be detected from the 5-years and decadal cycles of monthly and annual mean precipitation (Strahler and Strahler, 1997).
Sci. Technol. Arts Res. J., July-Sep 2015, 4(3): 129-138

The pattern of distribution of mean monthly rainfall on 5 -years cycles showed slight changes from the first to the second 5 years. Woliso obtained relatively high rainfall from 2004 through 2008 in 7/12 months (JFMASON) while it received relatively better rainfall in the second 5 years cycles, especially in the remaining $5 / 12$ months (MJJIAD; Figure 10). The amount of rainfall was found relatively higher during the main rainy months of the $2^{\text {nd }} 5$-years cycle than that of the $1^{\text {st }}$ cycle, with the exception of September (Figure 10).

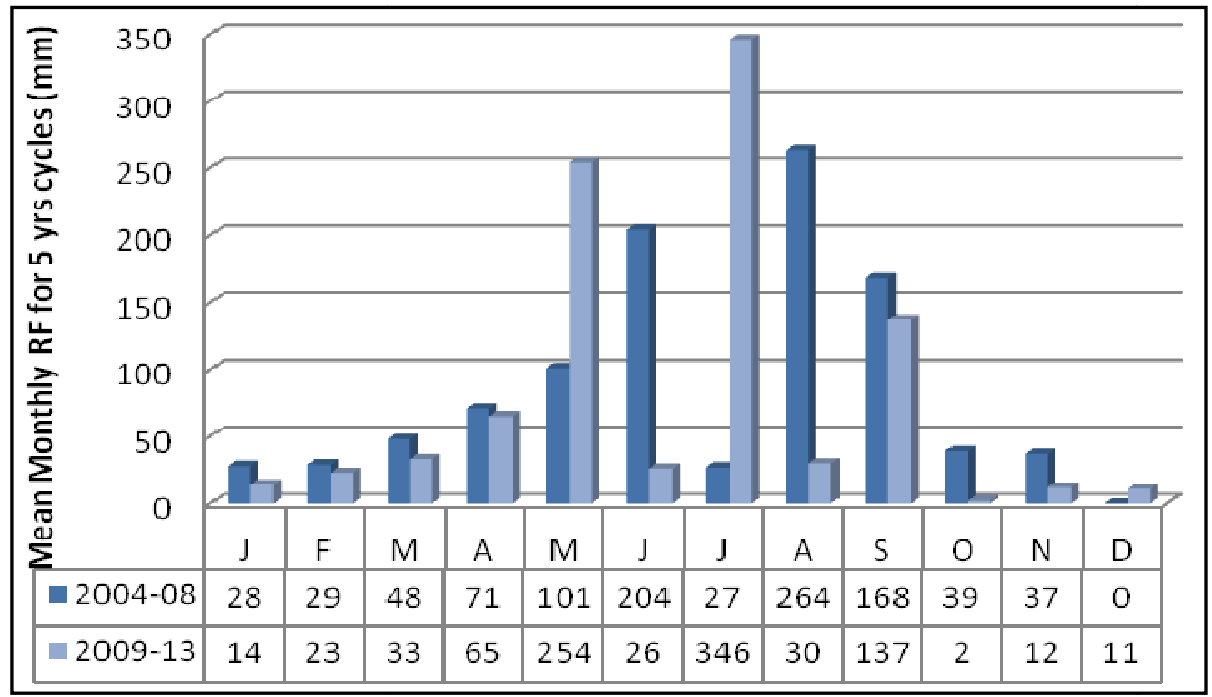

Figure 10: Distribution of mean monthly rainfall based on 5-years cycles

In most cases, there is variation between the actual annual total and the statistical annual average that can be identified using simple bookkeeping mathematics of the percentage of actual annual rainfall and the statistical annual average (usually called normal) for a given station (Raju 2012 cited in Solomon, 2013). It is the other measure of variability that is examined by taking the average deviation of each yearly value from the mean value (Strahler and Strahler 1997). A given year or month is considered as wet or dry based on whether respective rainfall of the requested period is above or below $25 \%$ from the normal rainfall, respectively. Based on this, the average annual rainfall of Woliso ranged between $968.5 \mathrm{~mm}$ in 2009 to $2,718.3 \mathrm{~mm}$ in 2012 with the decadal mean rainfall of about $1404.76 \mathrm{~mm}$ in the last decade. Only 2/10 years, namely 1410 and $2718.6 \mathrm{~mm}$ obtained above the decadal mean during 2006 and 2012, respectively (Figure $11 a$ and $b$ ). The most significant positive deviation was that of 2012, which deviated by about $100 \%$ from the aggregate/decadal mean, while highest negative deviation was identified in 2009 where the deviation from the mean was $<-30 \%$.

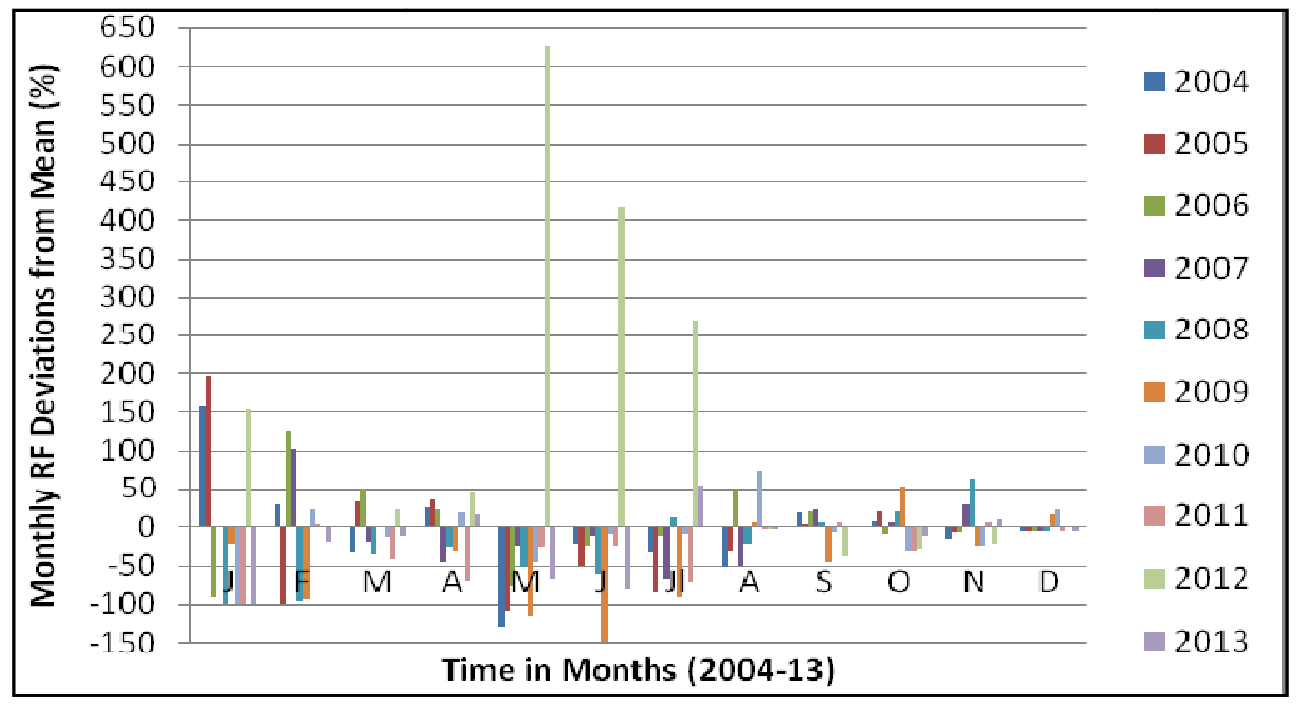

Figure 11a: Deviation of mean monthly rainfall from aggregate/decadal mean 

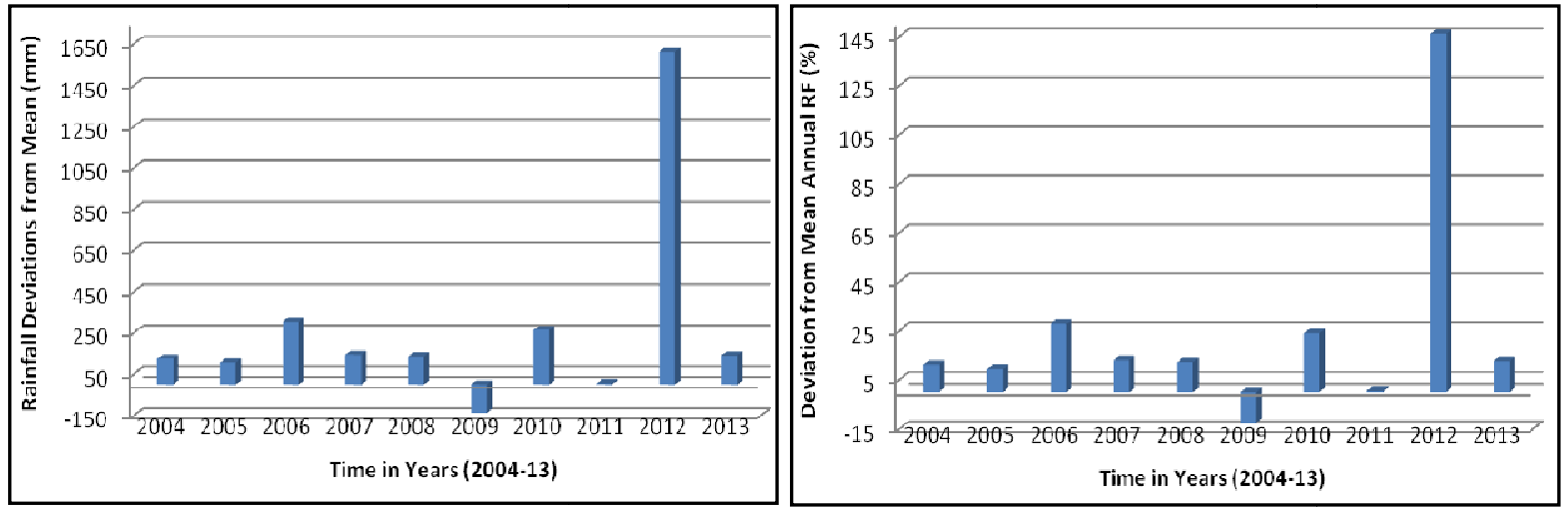

Figure 11b: Amount of (Left) and percentage (Right) of deviation of annual mean rainfall from decadal mean

With regards to the deviation of mean monthly rainfall from aggregate/decadal mean, 7 months (ONDJFMA) had significant decrease in the rainfall distribution as the percentage of deviation ranges from $-25 \%$ to $-75 \%$.

Whereas, 4 months (MJJIA) had significant increase in their mean rainfall as they showed positive deviation ranging from $25 \%$ to $125 \%$ (Figure $11 \mathrm{c}$ ).

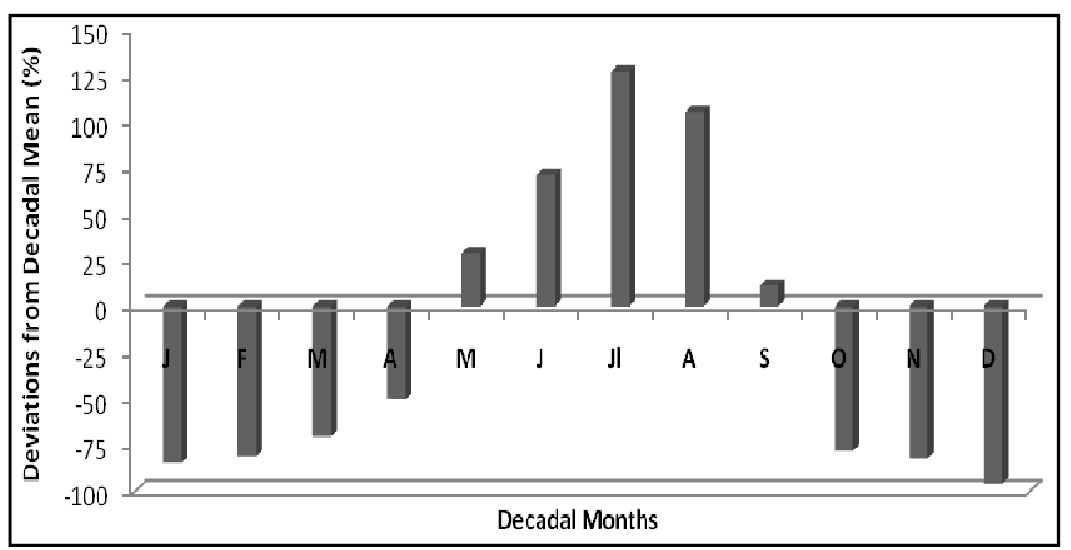

Figure 11c: Percentage of Deviation of Monthly Mean Rainfall from Decadal Mean
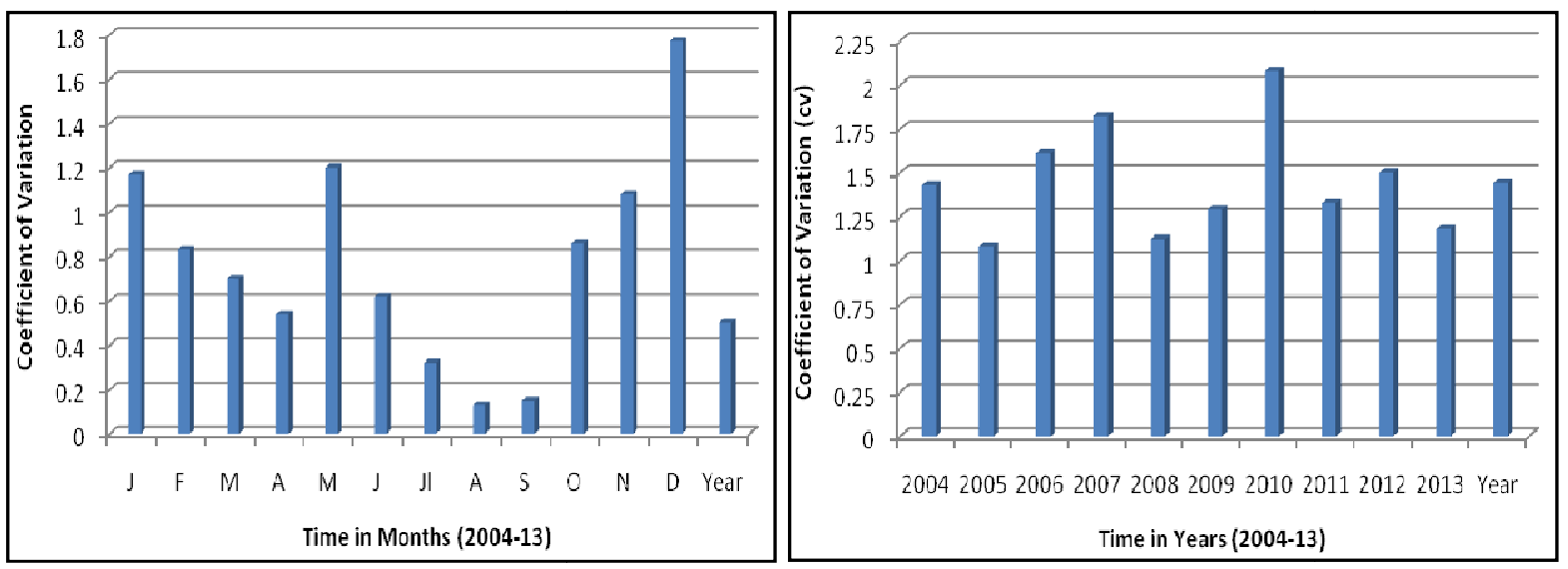

Figure 12: Coefficient of Variation for Monthly (Left) and Annual (Right) Mean Rainfall

As indicated in Strahler and Strahler (1997), CV is more stable and easy to remember than that of the standard deviation in the assessment of relative variability. Based on $\mathrm{CV}$, relative variability was about $57 \%$, indicating moderate variability in the mean monthly rainfall over the study period (2004-2013). This is further substantiated by observing the distribution of $\mathrm{CV}$, which ranges from 0.13 (January) to 1.77 (December) and the yearly average was 0.5 . Thus, about $67 \%(8 / 12)$ of the months experienced rainfall variability in the last one decade (Figure 15). Similarly, rainfall variability in the distribution of annual rainfall was computed using both relative variability and $\mathrm{CV}$. In the case of annual rainfall variability, the average variability was computed as $24 \%$ while the range of $\mathrm{CV}$ ranges from 1.1 (2005) to 2.1 (2010), with yearly $C V=1.4$. The years with rainfall variability higher than the yearly variability were 2006 , ' 07 , ' 10 and ' 12 while the rest were below the annual value (Figure 12). 
Solomon Tekalign

\section{Moisture Regions}

Despite the availability of different models and methods to estimate potential evapotranspiration (PET), the available data and advantage of its simplicity, Smith and Stoppes method (1978 cited in OIDA, 2007) was preferred as the data available for it in the contest of the
Sci. Technol. Arts Res. J., July-Sep 2015, 4(3): 129-138

study area. Based on this method, the PET of the study areas was estimated as under:

$$
\text { PET (in) }=\mathrm{T}\left({ }^{0} \mathrm{~F}\right)-32 / 9.5
$$

Where, PET (in) = Potential evapotranspiration in inch \& $T$ $\left({ }^{0} \mathrm{~F}\right)=$ Mean a monthly temperature in Degree Fahrenheit

Table 5: Distribution of monthly temperature, potential evapotranspiration and rainfall

\begin{tabular}{|c|c|c|c|c|c|c|c|c|c|c|c|c|}
\hline & Jan & Feb & Mar & Apr & May & Jun & Jul & Aug & Sep & Oct & Nov & Dec \\
\hline $\mathrm{T}\left({ }^{0} \mathrm{C}\right)$ & 20.01 & 22.11 & 21.40 & 20.81 & 19.38 & 18.13 & 17.18 & 17.55 & 17.97 & 19.17 & 18.73 & 19.26 \\
\hline $\mathrm{T}\left({ }^{0} \mathrm{~F}\right)$ & 68.01 & 71.79 & 70.51 & 69.45 & 66.88 & 64.63 & 62.92 & 63.58 & 64.35 & 66.50 & 65.71 & 66.66 \\
\hline PET $_{\text {(in) }}$ & 64.64 & 68.42 & 67.14 & 66.08 & 63.52 & 61.27 & 59.56 & 60.21 & 60.98 & 63.13 & 62.34 & 63.29 \\
\hline $\mathrm{PET}_{(\mathrm{mm})}$ & 164.19 & 173.79 & 170.54 & 167.85 & 161.33 & 155.61 & 151.27 & 152.94 & 154.88 & 160.35 & 158.34 & 160.76 \\
\hline $\mathrm{RF}(\mathrm{mm})$ & 35.45 & 28.9 & 44.97 & 75.83 & 177.19 & 235.31 & 312.09 & 282.48 & 152.7 & 29.91 & 24.33 & 5.6 \\
\hline Surplus & - & - & - & - & 15.86 & 79.70 & 160.82 & 129.54 & - & - & - & - \\
\hline Deficit & 128.74 & 144.89 & 125.57 & 92.02 & - & - & - & - & 2.18 & 130.44 & 134 & 155.16 \\
\hline
\end{tabular}

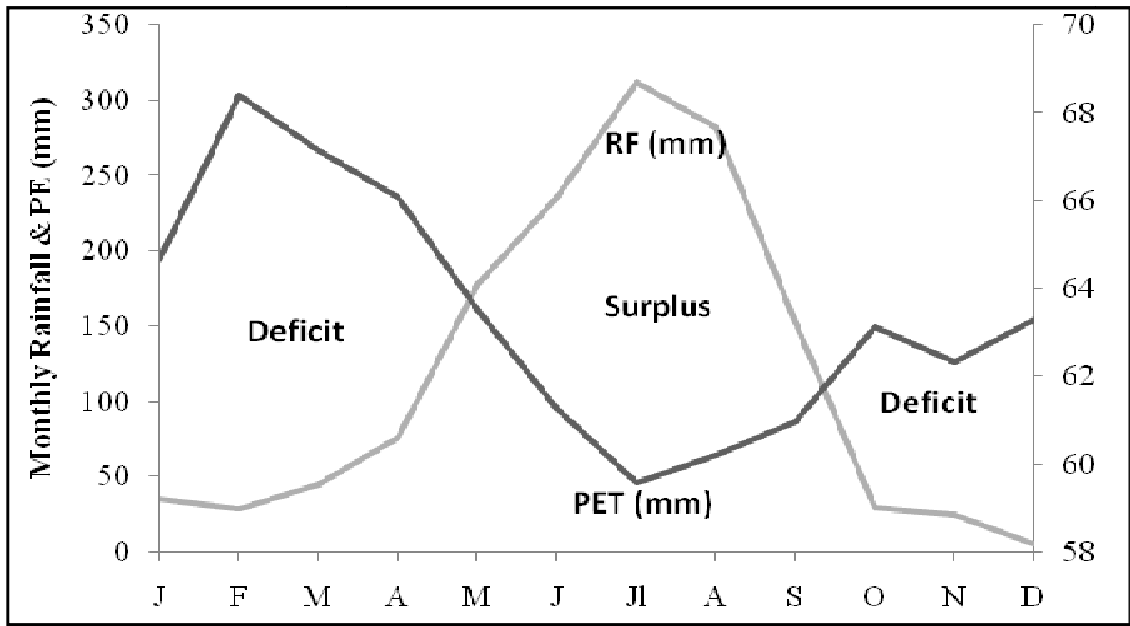

Figure 13: Monthly distribution of rainfall (RF) and potential evapotranspiration (mm)

Accordingly, the calculated potential evapotranspiration for all months in inch was converted into centimetres for the sake of comparison with rainfall amounts (Table 5 and Figure 13). Based on this, 4/12 $(33 \%)$ of the months (MJJIA) were with surplus rainfall, while $8 / 12(67 \%)$ of the months (SONDJFMA) experienced deficit in the rainfall distribution. This may imply that during the months of deficit, water supply for both agricultural and domestic purposes should be supplied through irrigation from underground water supply other integrated water harvesting technologies should be devised to balance the prevalence of water shortage in the area during these periods.

According to Thornthwaite's system (1955 employed in Daniel, 1977), water surplus and deficit can be used to define moisture index (Im). Likewise, the moisture region of the station is identified using the following formula:

$$
\mathrm{Im}=100(\mathrm{~S}-\mathrm{D}) / \mathrm{PE}
$$

Where, Im=moisture index, $S=a n n u a l$ water surplus, $D=a n n u a l$ water deficit, $P E=a n n u a l$ potential evapotranspiration and $r=a n n u a l$ precipitation.

Based on the S, D and PE, the Im of Woliso was -14 and thus it is classified under Dry subhumid $\left(\mathrm{C}_{1}\right)$ climatic types or moisture based on the Im based classification by
Barry and Chorley (1968 cited in Daniel (1977). Despite this fact, the water budget (or moisture balance) of Woliso was not computed for the lack of data on soil moisture storage change. This may be other area of further investigation for proper understanding and recommendation regarding moisture in the area.

\section{CONCLUSIONS}

The paper analysed the climate variability in Woliso area in West Shewa, Oromia Region, Central Ethiopia. It was identified that the climate types or moisture regions of Woliso was Dry subhumid $\left(\mathrm{C}_{1}\right)$. There was almost uniform temperature distribution in the last decade with slight variation in mean monthly temperature: in 2004, 2006, 2009 and 2012. The temperature variability of the last decade found slightly different the national amount reported by Muna (2006) and NMSA (2007). There were also significant deviations of monthly temperature from the mean temperature in the last decade. Regarding rainfall, there was almost uniform distribution with the exception of high rainfall in 2012 that showed significant trend of increase. About $90 \%$ of the years (2004-2013) had low to moderate intensity of rainfall. But there were dry months (ONDJFM) that call for water development activities to secure additional water supply for the life and livelihood of the community. In a nutshell, the current 


\section{Solomon Tekalign}

report the climate data was based on only one decade and there was lack of data on soil moisture storage change to compute on water balance for the study area. Thus, it requires further investigation to substantiate some of the findings identified by this report.

\section{Conflict of Interest}

Author declared no conflict of interest.

\section{Acknowledgments}

The author acknowledges Mr Getachew Gomoro and Dr U.R. Reddy for accessing with relevant data and the NMSA for provision of meteorological data.

\section{REFERENCES}

Alvi, Z. (1995). Statistical Geography: Methods and Applications. Rawat Publications, New Delhi, India.

Awol Akmel Yesuf. (2010). A Study on the Changing Urban Environment of Addis Ababa City, Ethiopia through Remote Sensing and GIS. PhD Thesis. Department of Geography, Andhra University, India.

Chaudhary, P., and Aryal, K.P. (2009). Global Warming in Nepal: Challenges and Policy Imperatives. Journal of Forest and Livelihood 8(1): 5-14.

Daniel Gemechu. (1977). Aspects of Climate and Water Budget in Ethiopia. Addis Ababa University Press, Addis Ababa, Ethiopia.

EEA (Ethiopian Economics Association). (2014). Report on the Ethiopian Economy: Small and Micro Enterprises (SMEs), Development in Ethiopia: Policies, Performances, Constraints and Prospects. EEA. United Printers. Addis Ababa, Ethiopia.

Getachew Gomoro., Solomon Tekalign and Reddy, R.U. (2014). Climate Variability, and its Local Perception and Adaptation Measures in Woliso Woreda, Ethiopia, East Africa. International Journal of Science and Research 3(11): 1510-1515.
Sci. Technol. Arts Res. J., July-Sep 2015, 4(3): 129-138

IPCC. (2001). Climate Change Impacts, Adaptation and Vulnerability. IPCC Working Group II, Third Assessment Report. Cambridge, Cambridge University Press.

IPCC (2007). Fourth Assessment Report. Available at: http://195.70.10.65/publications and data/ publications ipcc fourth assessment report synthesis report.htm [Accessed 01/06/2015].

Koul, L. (1994). Methodology of Educational Research. $2^{\text {nd }}$ ed. Vikas Publishing House Pvt. Ltd. New Delhi. India.

Muna, H. (2006). Variation and trends in observed temperatures in the Ethiopian highlands (1973-2003). M.A Thesis, Addis Ababa University.

NMSA (2007). Climate change National Adaptation Program of Action (NAPA) of Ethiopia. Addis Ababa, Ethiopia.

OIDA (Oromia Irrigation Development Authority), (2007). Fentale Irrigation Based Integrated Development Feasibility Study and Engineering Design: Integrated Watershed Management and Forest Assessment Plan. OWWDSE, Finfinne.

Snedecor, G.W. and Cochran, W.G. (1989). Statistical Methods. $8^{\text {th }}$ ed. lowa State University Press. lowa, USA.

Solomon Tekalign Demissie. (2013). Analysis of Environmental Resources, Climate Change and Livelihood Strategies in Hararghe Highlands, Eastern Ethiopia. PhD Thesis. Department of Geography. Faculty of Science, Andhra University. India.

Strahler, A. and Strahler, A. (1997) Physical Geography: Science and Systems of the Human Environment. John Wiley \& Sons, Inc. USA.

Valdivia, C. and Quiroz, R. (2003). Coping and Adaptation to Increased Climate Variability in the Andes. Paper Prepared for Presentation at the American Agricultural Economics Association Annual Meeting. Montreal, Canada held July 27-30, 2003.

WHO (2004). The World Health Report 2003: shaping the future. WHO, Geneva. Available at: http://www.int/whr/20 03 /e n/index.html [Accessed on 18 December 2014]. 